\title{
Recovery from paraplegia following aortic saddle embolism. Case report
}

\author{
G Chandrashekar MS MCh, ${ }^{1} \mathrm{P}$ T Acharya MD DM,${ }^{2} \mathrm{~J}$ Rao MD,${ }^{3}$ R S Kumar MS, ${ }^{1}$ \\ G Nayak MS DABS ${ }^{1}$ \\ ${ }^{1}$ Department of Cardiovascular and Thoracic Surgery, ${ }^{2}$ Department of Neurology, M.S. \\ Ramaiah Institute of Cardiology, New B.E.L. Road, Gokula, Bangalore-560054, India; \\ ${ }^{3}$ Consultant Radiologist, Manipal Hospital, Bangalore, India.
}

\begin{abstract}
An aortic saddle embolus causing paraplegia is rare and even rarer is a documentation of neurological recovery from this event. A 47 year old male presented with absent pulsations in the lower limbs and paraplegia, both of sudden onset. He underwent immediate bilateral transfemoral embolectomy. The postoperative period was stormy. The paraplegia recovered over a period of 2 months and he could walk to his place of work after 6 months. The rare combination of saddle embolus and paraplegia is discussed. An attempt has been made to verify the hypothesis of Dickson et al which states that a low origin of the great radicular artery (GRA) below T12 level may be responsible for paraplegia when obstructed by a saddle embolus. We found the GRA arising at L2 vertebral level in this patient. Postoperative selective spinal arteriogram and magnetic resonance imaging (MRI) of the spinal cord showed a patent GRA and normal spinal cord structure respectively. Early surgical intervention in restoring the blood flow into the GRA may prevent severe histological changes hitherto responsible for nonrecovery from paraplegia in the earlier reports.
\end{abstract}

Keywords: embolism; aorta; paraplegia; spinal cord; selective angiography.

\section{Introduction}

Saddle embolism of the aorta is a rare but serious complication of an underlying cardiac disease. ${ }^{1.2}$ Although many a life and limb has been saved with the advent of heparin and early embolectomies, ${ }^{3.4}$ what intrigues is the rare complication of paraplegia following the total occlusion of the aortic bifurcation by an embolus. Literature is scarce regarding the incidence and recovery from paraplegia complicating a saddle embolus. ${ }^{5-7}$

\section{Case report}

A 47 year old man was admitted to hospital on 11th October 1992 at 11 am with a history of sudden onset an hour previously of severe pain in the lower back and both lower limbs with inability to move both lower limbs and numbness. He was a known diabetic (NIDDM) on oral hypoglycaemic agents with 'good' control. There was a history of chest pain about a week previously.
He was seen on arrival by a senior registrar who observed the patient to have severe agonising pain. The femoral, popliteal, dorsalis pedis and posterior tibial arterial pulses in both lower limbs could not be felt. His skin was cold from umbilicus distality. There was no skin mottling. Flaccid total paralysis of both lower limbs with loss of all modalities of sensation and loss of tendon and superficial reflexes were found. The urinary bladder was distented and catheterisation drained $1500 \mathrm{ml}$ of urine. Details of sacral sparing, of the bulbocavernous and anal reflexes, of anal tone, and of urinary bladder sensation were not available from the initial examination. A diagnosis of saddle thrombus with flaccid paraplegia was made, and an immediate bilateral transfemoral embolectomy was performed. As the patient was taken to surgery immediately, the progression of any spinal neurological changes was not available preoperatively. However detailed postoperative serial neurological examinations were carried out by a consultant neurologist (Table I).

Normal blood supply was established in both lower limbs within 7 hours of the onset of symptoms. The patient had relief of pain and 
Table I Serial neurological examination data

\begin{tabular}{|c|c|c|c|}
\hline Motor system & $11 / 11 / 92$ & $17 / 12 / 92$ & $15 / 4 / 92$ \\
\hline Tone & $\begin{array}{l}\text { Flaccidity both lower } \\
\text { limbs }\end{array}$ & $\begin{array}{l}\text { Flaccidity both lower } \\
\text { limbs }\end{array}$ & $\begin{array}{l}\text { Mild hypotonia, } \\
\text { bilateral }\end{array}$ \\
\hline Power & $\begin{array}{l}\text { Right lower limb: } \\
\text { grade } 4-5 \text {. Left } \\
\text { lower limb: proximal } \\
\text { grade } 3-5 \text {, distal } \\
\text { grade } 2-5\end{array}$ & $\begin{array}{l}\text { Right lower limb: } \\
\text { grade } 4+-5 \text {. Left } \\
\text { lower limb: proximal } \\
\text { grade } 4-5 \text {, distal } \\
\text { grade } 3-5\end{array}$ & $\begin{array}{l}\text { Right lower limb: grade } \\
4+-5 \text {. Left lower limb: } \\
\text { proximal grade } 4+-5 \text {, } \\
\text { distal grade } 4+-5\end{array}$ \\
\hline Nutrition & $\begin{array}{l}\text { Mild wasting of } \\
\text { muscles below the } \\
\text { knee bilaterally }\end{array}$ & $\begin{array}{l}\text { Mild wasting of } \\
\text { muscles below the } \\
\text { knee bilaterally }\end{array}$ & No wasting seen \\
\hline \multirow[t]{3}{*}{ Sensory system } & $\begin{array}{l}\text { Marked blunting of } \\
\text { touch and pain } \\
\text { perception below L1 } \\
\text { level on both sides }\end{array}$ & $\begin{array}{l}\text { Mild blunting of touch } \\
\text { and pain perception } \\
\text { below L2 level on } \\
\text { both sides except the } \\
\text { perianal area }\end{array}$ & $\begin{array}{l}\text { Mild blunting of touch } \\
\text { and pain in L3-S2 } \\
\text { segments bilaterally }\end{array}$ \\
\hline & $\begin{array}{l}\text { Position and vibration } \\
\text { sense lost in both } \\
\text { lower limbs }\end{array}$ & $\begin{array}{l}\text { Position and vibration } \\
\text { sense lost in both } \\
\text { lower limbs }\end{array}$ & $\begin{array}{l}\text { Position sense: normal } \\
\text { bilaterally } \\
\text { Vibration: knee } \\
\text { normal, ankle absent }\end{array}$ \\
\hline & $\begin{array}{l}\text { No sacral sparing, } \\
\text { severe burning } \\
\text { parasthesiae in the } \\
\text { legs }\end{array}$ & $\begin{array}{l}\text { Sacral sparing present, } \\
\text { burning parasthesiae } \\
\text { less }\end{array}$ & $\begin{array}{l}\text { Sacral sparing present, } \\
\text { no painful parasthesiae }\end{array}$ \\
\hline Tendon jerks & $\begin{array}{l}\text { Knee and ankle jerks } \\
\text { absent bilaterally }\end{array}$ & $\begin{array}{l}\text { Knee and ankle jerks } \\
\text { absent bilaterally }\end{array}$ & $\begin{array}{l}\text { Knee and ankle jerks } \\
\text { absent bilaterally }\end{array}$ \\
\hline Plantar response & $\begin{array}{l}\text { Not elicitable } \\
\text { bilaterally }\end{array}$ & $\begin{array}{l}\text { Flexor response } \\
\text { bilaterally }\end{array}$ & $\begin{array}{l}\text { Flexor response } \\
\text { bilaterally }\end{array}$ \\
\hline Anal tone & Weak & Normal & Normal \\
\hline $\begin{array}{l}\text { Bladder sensation and } \\
\text { micturition }\end{array}$ & Normal & Normal & Normal \\
\hline Anal reflex & Sluggish & Normal & Normal \\
\hline Bulbocavernous reflex & Absent & Absent & Normal \\
\hline Remarks & $\begin{array}{l}\text { Distal spinal cord and } \\
\text { cauda equina } \\
\text { ischaemia with flaccid } \\
\text { paraplegia }\end{array}$ & $\begin{array}{l}\text { Recovering flaccid } \\
\text { paraparesis }\end{array}$ & $\begin{array}{l}\text { Recovering flaccid } \\
\text { paraparesis }\end{array}$ \\
\hline
\end{tabular}

return of lower limb pulsations, but the paraplegia persisted in the immediate postoperative period. He also developed acute renal failure which recovered within 3 weeks. One month after the event he was seen by a consultant neurologist who confirmed the diagnosis of flaccid paraplegia with localisation to the distal spinal cord or cauda equina (Table I). MRI (Figs 1,2) of the lumbar spine performed 1 month after the vascular event showed a normal conus medullaris and cauda equina.
Selective spinal arteriograms were done to assess postoperative vascular patency from $\mathrm{T} 8$ to L4 levels (Fig 3), which demonstrated a patent great radicular artery (artery of Adamkiewicz) arising uncommonly at L2 vertebral level. Electroneuromyography (ENMG) and nerve conduction studies done on 23rd December 1992 showed evidence of diffuse axonal damage in both lower limbs.

The patient made a good recovery from paraplegia during his hospital stay of 2 months, 


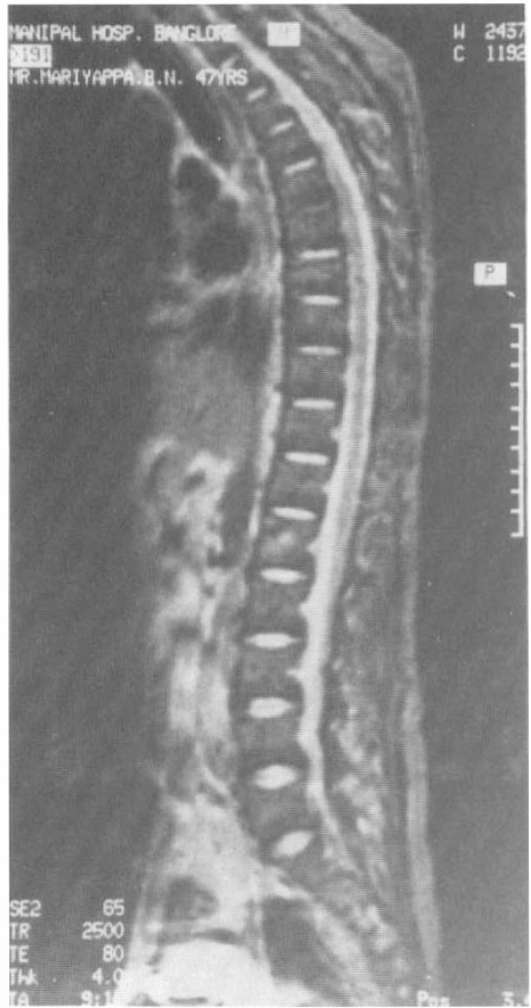

Figure 1 MRI showing sagittal scan of the entire spine using T2-weighted spin echo sequence using body coil showing normal cord and CSF. Note normal vertebral and disc signals also (SE/2500/15/80/4).

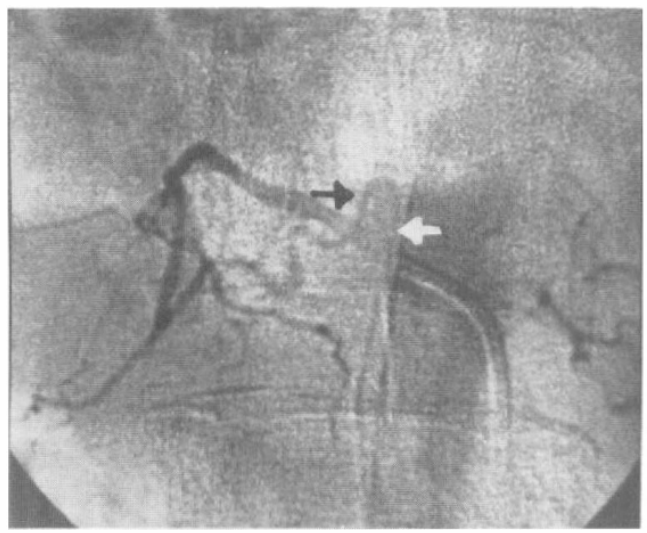

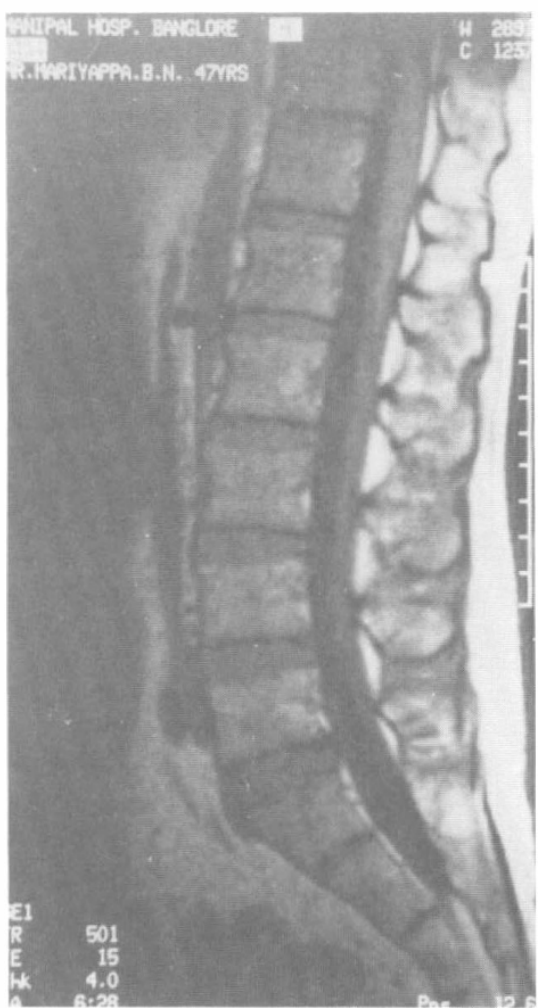

Figure 2 MRI of the lumbar spine using T1weighted spin echo sequence in the sagittal plane showing normal conus and cauda equina (SE1/TR501/15/4).

\section{b}

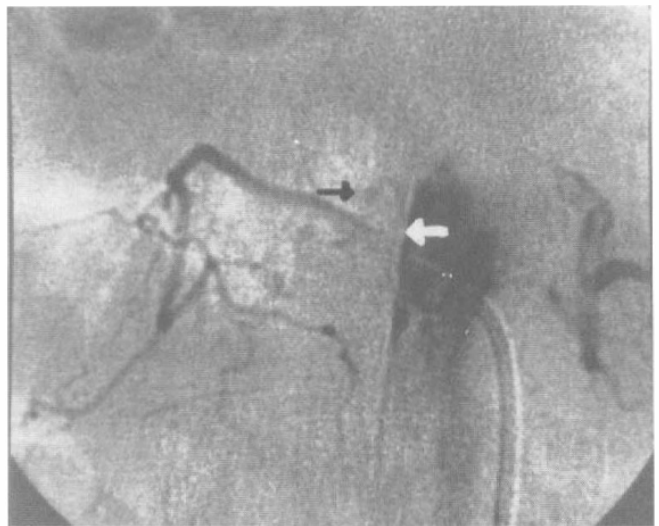

Figure 3 Digital subtraction spinal arteriograms showing typical hair pin bend of artery of Adamkiewicz (GRA) (black arrow) with descending loop of the anterior spinal artery (white arrow) at L2 vertebral level. (a) AP view. (b) Oblique view. 
regaining bladder control and motor power in both lower limbs (Table I). He was placed on oral anticoagulant therapy on discharge.

\section{Discussion}

Paraplegia is a rare complication following an aortic saddle embolus. ${ }^{5-7}$ In order to understand the association of saddle embolus and paraplegia it is necessary to consider the arterial supply of the distal spinal cord and cauda equina. The main arterial supply of the distal spinal cord is from the artery of Adamkiewicz (GRA) though it may receive liberal collateral circulation from the branches of the internal iliac artery; but the cauda equina is known to derive most of its blood supply from the lateral and medial sacral arteries arising from the internal iliac artery. ${ }^{8}$ Why is paraplegia rare following saddle embolus? The GRA commonly arises between T8 and T12 vertebral levels and it reinforces the arterial blood supply arising segmentally. ${ }^{8}$ Saddle embolus, lodging at the bifurcation of the aorta, may not jeopardise the usual higher origin of the GRA. It has been hypothesized by Dickson et al that an aortic saddle embolus may obstruct and/or lead to proximal thrombosis of the GRA arising at an unusually low level (below T12 level), and result in distal spinal cord ischaemia or infarction and paraplegia. ${ }^{7}$ Interestingly, no attempt has been made so far to prove or disprove this hypothesis; the rarity of such events could be a reason. The demonstration of a large serpiginous spinal radicular artery going cephalad and taking a hair pin bend towards the distal spinal cord in our patient may well be the GRA in question. ${ }^{9.10}$ This arose from as low a level as L2.

In a review of 11 cases of spinal stroke by Silver et $a l^{5}$ only one patient had paraplegia due to a saddle embolus. In that report, despite embolectomy being performed presumably within 12 hours after the event, the recovery from paraplegia with near normal bladder control took nearly 6 months. The recovery, however, has been disclaimed later by the same author in another article. ${ }^{6}$ The embolectomy in Dickson et al's case was done later than 21 hours after the onset of symptoms. ${ }^{7}$ This may explain the failure of recovery from paraplegia in his case. Three pertinent points emerge here: the low origin of the GRA; the total ischaemia time from embolism to its relief by embolectomy; and reversibility of spinal cord damage (reversible ischaemia). In both the previous case reports of paraplegia following saddle embolus, the low origin of the GRA was not confirmed. The duration of ischaemia was too long in Dickson et al's report (21 hours). ${ }^{7}$ The ischaemia time was presumably around 12 hours in Silver et al's case judging from the chronology of events mentioned in that case report. ${ }^{5}$ This fact may explain the irreversibility of the spinal cord damage in both cases.

Interestingly, the postmortem examination of Dickson et al's case, when the patient succumbed to a repeat saddle embolus, showed occlusion by the thrombus of the distal aorta and its bifurcation. The distal spinal cord showed widespread damage with cell death and severe degeneration of almost all neurons. ${ }^{7}$ In Dr Silver's review ${ }^{5}$ he discusses the pathogenesis of cord lesions due to ischaemia following spinal stroke in the autopsied specimens. He has found, in the absence of a permanent block by way of a thrombus, that the histological changes that occur may be relatively mild. He also says: 'The absence of major histological change may explain the neurological recovery in many cases'.

An attempt at an aortogram and a selective spinal arteriogram could ideally have been made in the preoperative period; but practical considerations as regards the emergency nature of the condition and the purely academic nature of these investigations at that time did not warrant such time consuming procedures, which could only have aggravated the patient's condition and jeopardised the success of surgery by increasing the ischaemia time. However, postoperative assessment of the spinal cord blood supply done in view of the persisting paraparesis revealed a low origin of the GRA (which could in all probability have been blocked by the thrombus in the distal aorta at the mouth of the lumbar artery L2 level). The literature so far reviewed repeatedly implicates an aortic saddle embolus to be the probable cause of paraplegia 
when this occurs in the anatomical setting of a low origin of the GRA. Taking this instance as a case in point, it may appear that the two incontrovertible facts of saddle embolus and a low origin of the GRA may account for paraplegia, however much one may make attempts to ascribe their associations as merely coincidental. Unfortunately there is no large series in the world literature to date documenting an overwhelming definitive statistical correlation between saddle emboli causing paraplegia and surgical results that could corroborate the statement that early embolectomy is of proven value and is mandatory for restoration of spinal cord function. It is agreed that at best it is simplistic to draw this conclusion considering the rarity of such events, and their inability to survive a statistical test. In the light of the pathological studies done earlier, and in the light of a few cases that either did not recover or observations regarding recovery being controversial, ${ }^{11}$ this is a singular case that provides clinical and investigational data to throw light on both cause and effect in terms of clinical morbidity and demonstrates recovery following timely surgery, results that could have been anticipated if one were to take prior clinicopathological correlates and extrapolations seriously.

It is clear from the above discussion that when the clinical combination of paraplegia complicating a saddle embolus is recognised, early and aggressive surgical intervention is indicated.

\section{References}

1 Busuttil Ronald W, Keehn G, Milliken J. Paredero VM, Baker JD, Machleder HI et al (1983) Aortic saddle embolus A twenty-year experience. Ann Surg 197: 698-706.

2 Littooy FN, Baker WH (1985) Ruptured abdominal aortic aneurysm. In: Bernhard VM, Towne JB, editors. Complications in Vascular Surgery. 2nd ed. Grune \& Stratton Inc. Orlando FL: 133-139.

3 Deterling RA Jr, Vargas LL. McAllister FF (1962) Follow up studies of patients with embolic occlusion of the aortic bifurcation. Ann Surg 155(5): 383-391.

4 Panetta T, Thompson JE, Talkington CM. Garrett Wilson V. Smith BL (1986) Arterial embolectomy: A 34-year experience with 400 cases. Surg Clin North Am 66(2): 339-353.

5 Silver JR, Buxton PH (1974) Spinal stroke. Brain 97(Part III): 539-550.

6 Silver JR (1986) Letter to the Editor. Paraplegia 24: 336.

7 Dickson AP, Lum SK, Whyte AS (1984) Paraplegia following saddle embolism. Br J Surg 71(4): 321.

8 Elliot JP Jr, Szilagyi DE, Hageman JH, Smith RF. Reddy JD (1985) Spinal cord ischaemia: secondary to surgery of the abdominal aorta. In: Bernhard VM. Towne JB, editors. Complications in Vascular Surgery. 2nd ed. Grune \& Stratton Inc, Orlando FL: 291-310.

9 Doppman JL, Di Chiro G, Morton DL (1968) Arteriographic identification of spinal cord blood supply prior to aortic surgery. JAMA 204(2): 172-173.

10 Di Chiro G, Wener L (1973) Angiography of the spinal cord. A review of contemporary techniques and applications. J Neurosurg 39: 1-27.

11 Chandrashekar G (1993) Letter to the Editor. Paraplegia 31: 415. 